\title{
CARACTERIZAÇÃO E ANÁLISE DO POTENCIAL DA ÁGUA PRODUZIDA COMO ALTERNATIVA PARA REUSO
}

\author{
A.M.A.BARBOSA ${ }^{1}$, J.L.TAVARES, J.A.NAVONI \\ Instituto Federal de Educação, Ciência e Tecnologia do Rio Grande do Norte \\ mab.andreza@hotmail.com ${ }^{1}$
}

Artigo submetido em 25/11/2019 e aceito em 11/12/2019

DOI: $10.15628 /$ holos. 2019.9200

\begin{abstract}
RESUMO
Em regiões semiáridas, a escassez hídrica é uma problemática que põem em risco a sustentabilidade do desenvolvimento socioeconômico regional. Diante disso, o presente trabalho teve como intuito avaliar a qualidade da água produzida proveniente da indústria petrolífera no nordeste brasileiro no município de Mossoró-RN e seu potencial uso na irrigação. Amostras de água produzida foram avaliadas para caracterização físico-químicas $(\mathrm{pH}$, condutividade, sólidos totais dissolvidos, salinidade, alcalinidade, carbonato, bicarbonato, cálcio, magnésio, dureza, cloreto, sódio, potássio, nitrato, sulfato, ferro) e toxicológicas (metais pesados: cádmio, cobre, chumbo, cromo, manganês, níquel, zinco e alumínio além do TOG). No que diz respeito às análises físico-químicas, os valores de
\end{abstract}

$\mathrm{NaHCO}_{3}, \mathrm{Ca}^{2+}, \mathrm{Mg}^{2+}, \mathrm{K}^{+}$e $\mathrm{Cl}^{-}$estiveram fora dos limiares considerados pelo manual de irrigação da EMBRAPA. Para as análises toxicológicas, todos os metais ficaram conformes e apenas o TOG extrapolou o limite permitido pela CONAMA no 430/2011, que trata sobre a gestão do lançamento de efluentes, indicando a necessidade de incorporação de processos para eliminar e/ou minimizar a ocorrência destes compostos, uma vez que a água utilizada neste estudo era um efluente, sem qualquer tipo de tratamento, garantindo a segurança sanitária deste recurso em práticas de irrigação. Sendo assim, a água produzida pode ser considerada um recurso hídrico alternativo para irrigação após tratamento adequado.

\section{CHARACTERIZATION AND ANALYSIS OF PRODUCED WATER POTENTIAL AS AN ALTERNATIVE FOR REUSE}

\begin{abstract}
In semiarid regions, water scarcity is a problem that risk the sustainability of regional socioeconomic development. The present work aimed to evaluate the quality of produced water from the oil industry in northeastern Brazil in the municipality of Mossoró - RN and its potential use in irrigation. Produced water samples were evaluated for physicochemical characterization $(\mathrm{pH}$, conductivity, total dissolvedsolids, salinity, alkalinity, carbonate, bicarbonate, calcium, magnesium, hardness, chloride, sodium, potassium, nitrate, sulfate, iron) andtoxicological (metals), heavy duty: cadmium, copper, lead, chrome, manganese, nickel, zinc and aluminum in addition to TOG. Regarding the physicochemical analyzes, $\mathrm{NaHCO}_{3}, \mathrm{Ca}^{2+}, \mathrm{Mg}^{2+}, \mathrm{K}^{+}$
\end{abstract}

and $\mathrm{Cl}^{-}$values were outside the thresholds considered by the EMBRAPA irrigation manual. For toxicological analysis all metals were compliant and only TOG exceeded the limital lowed by CONAMA $n^{\circ} 430 / 2011$ which deals with the management of effluent discharge, indicating the need to incorporate processes to eliminate and or minimize the occurrence of these compounds, since the water used in this study was an effluent, without any treatment, ensuring the sanitary safety of this resource in irrigation practices. Thus, the produced water can be considered an alternative water resource for irrigation after proper treatment.

KEYWORDS: Produced Water, Water quality, Reuse. 


\section{INTRODUÇÃO}

O petróleo é um combustível de origem fóssil, cuja composição advém de matéria orgânica que, ao longo de milhares de anos, se deposita em reservatórios de rochas sedimentares, as quais, com o auxílio de fatores como temperatura e pressão, dão origem ao petróleo. No reservatório conjugado ao óleo, têm-se outros dois fluidos: a água e o gás natural. Durante o processo produtivo do petróleo, a geração de resíduos como lamas oleosas, águas residuais, compostos orgânicos voláteis, resíduos de catalisador do processo de destilação, além da ocorrência de metais tóxicos, entre outros, é inevitável. Dentre esses subprodutos, a água produzida (AP) se destaca devido às grandes quantidades geradas em todas as etapas (extração, transporte e refino) do processo de produção (Srikanth, Kumar, \& Puri, 2018).

A água produzida nos campos petrolíferos é aquela trazida à superfície durante a extração de petróleo ou do gás. Por definição, tem-se que a água produzida é o efluente resultante dos processos de separação existentes nas estações coletoras e de tratamento na produção de petróleo (Garnica, Cubelo, Araujo, \& Braga, 2017). Esta água pode ter origem do próprio reservatório de petróleo, no contato com aquíferos subterrâneos adjacentes a esse local, ou pode ser água injetada no poço em projetos que visam aumentar a recuperação de óleo (Jiménez, Micó, Arnaldos, Derrero, Malfeito, Medina, \& Contreras, 2017; Venkatesan \& Wankat, 2017; Li, Guo, Zhang, \& Liu, 2014). A AP pode limitar a vida produtiva de poços de óleo e gás e causar problemas graves como, por exemplo, a corrosão tubular. Esse rejeito representa o maior fluxo de resíduos associado à indústria petrolífera (Hosny, Fathy, Ramzi, \& Abdel, 2016).

A corrente de fluido atinge diretamente aspectos ambientais e econômicos associados à produção de petróleo e gás. Além disso, essa água pode conter alta salinidade, alta concentração de metais, contaminantes orgânicos e inorgânicos, material radioativo, dentre outros elementos conhecidos por serem prejudiciais à saúde humana e ao meio ambiente (Dolan, Cath, \& Hogue, 2018). No entanto, a amplitude e a grandeza do impacto ambiental causado pela água produzida não são contínuas, pois suas consequências oscilam de acordo com a região onde a atividade está inserida, bem como com o tempo de exposição aos fatores agressores, dimensões de projeto, medidas preventivas, preditivas e corretivas adotadas para minimizar os resultados danosos (Gomes, 2014).

Algumas normatizações estabelecem diretrizes para minimizar os danos ambientais gerados e para assegurar a qualidade dessa água quando descartada ou reutilizada. No Brasil, tem-se, no que diz respeito a esse assunto, a resolução 430/2011 do Conselho Nacional do Meio Ambiente (CONAMA), que trata sobre a gestão do lançamento de efluentes, alterando parcialmente e complementando a resolução CONAMA 357/2005 (outras legislações específicas para cada fim são Resolução CNRH № 15/2001, Resolução CONAMA 396/2008, entre outras). No âmbito internacional não é diferente. A Federal Water Pollution Control ACT/2002, por exemplo, é uma lei que tem por objetivo manter a integridade das águas em todos os aspectos. Mesmo com todas essas diretrizes, sabe-se que, independente de qual será o seu destino final, os resíduos necessitam ser tratados para diminuir sua nocividade. Jiménez et al. (2017), indica que a redução da turbidez, remoção de óleos e graxas, fenóis, ferro dentre outros compostos são 
fundamentais para tornar essa água uma fonte segura de reúso. O estudioso também destaca tecnologias avançadas de tratamento de água como filtração por membrana, biorreator de membrana, evaporadores térmicos ou processos de oxidação avançada, ressaltando que deve ser minimizado o consumo de produtos químicos para redução de sólidos suspensos e conteúdo orgânico.

Após o tratamento adequado, com remoção e/ou adequação de todos os contaminantes acima citados, a água residual da produção de petróleo e gás pode ter diferentes aplicações, podendo ser utilizada na agricultura (irrigação e estoque), usos urbanos (abastecimento de água da cidade) e usos industriais (construção e processamento) (Mallants, Simunek, \&Torkzaban, 2017). No entanto, uma série de fatores pode influir nas características finais desse efluente, tais comoas características geológicas da área de estudo eas caraterísticas físicas e químicas finais do produto tratado em virtude de analisar a viabilidade do reúso e os impactos ambientais causados pela AP de petróleo.

Em face ao relatado, este artigo tem por finalidade realizar a caracterização físico-química e toxicológica de amostras de água produzida de petróleo, oriunda da região de exploração petrolífera no RN. Para tal efeito, amostras de água produzida da região Mossoró-RN foram obtidas de 20 poços ativos, distribuídos em 14 estações coletoras, das quais uma está desativada.

\section{REFERENCIAL TEÓRICO}

A escassez hídrica é uma problemática mundial, em particular nas regiões semiáridas. No Brasil, a região semiárida nordestina apresenta condições hídricas desfavoráveis, o que se intensifica devido às caraterísticas geológicas que impedem a acumulação de água no solo (CPRM, 2018). A questão se torna mais urgente em momentos como os observados nos últimos 10 anos, espaço de tempo em que a região enfrentou mais um período de seca extrema, considerado o pior dos últimos 50 anos (Martins, Magalhães, \& Fontenele, 2017). Diante desse cenário, o reúso - definido como a reutilização da água em outras atividades) - surge como um instrumento de gestão dos recursos hídricos que influencia o desenvolvimento regional, desde que se tenha o conhecimento prévio do seu grau de perigo à saúde e ao ambiente (Mancuso \& Santos, 2003).

Na cadeia de produção petrolífera, a água (denominada água produzida ou AP) se destaca como subproduto devido às grandes quantidades geradas em todas as etapas (extração, transporte e refino) de produção (Srikanthet al., 2018). No Brasil, os maiores volumes de AP ocorrem nos estados do Rio de Janeiro (RJ) e do Rio Grande do Norte (RN). A produção de água aumenta com a maturidade do poço, podendo se aproximar de $100 \%$ da produçãoà medida que o poço chega ao fim de sua vida produtiva (Assunção, Vieira, Almeida, 2018). No RN, a geração de AP triplicou nos últimos 10 anos, atingindo mais de 7 milhões de metros cúbicos em 2018 (BRASIL, 2017). Como mencionado anteriormente,essa água pode ter origem no próprio reservatório de petróleo quando entra em contato com aquíferos subterrâneos ou pode ser água injetada no poço com vista à recuperação de óleo. Em geral, a AP possui elevada salinidade, além de que o contato com outros resíduos como lamas oleosas, resíduos de catalisador do processo de destilação, presença de compostos orgânicos voláteis e metais dentre outras substâncias faz 
com que sua composição química possa causar impactos ambientais e econômicos, como também gerar potenciais riscos sanitários.

Nessa perspectiva, a AP é considerada o rejeito com o maior fluxo de contaminantes associado à geoquímica da área de exploração petrolífera (Hosny et al., 2016; Dolan et al., 2018; Jiménez, Micó, Arnaldos, Derrero, Malfeito, Medina, \& Contreras, 2018). A amplitude e a grandeza do impacto ambiental dependem de fatores tais como a região onde a atividade está inserida, as dimensões de projeto e a existência ou não de medidas preventivas, preditivas e corretivas a serem adotadas para minimizar danos (Gomes, 2014). Sendo assim, a utilização de AP no reuso possui grande potencialidade, uma vez que salienta a mitigação do estresse hídrico em regiões atingidas pela seca e contribuina minimização de impactos ambientais (Sousa, Crisostomo, Weber, Escobar, \& Oliveira, 2016).No entanto, as caraterísticas químicas da AP precisam ser definidas para que se possam caracterizar os riscos atrelados a ela, bem como as tecnologias necessárias para a adequação necessária a determinados usos.

\section{OBJETIVOS}

\section{a. Objetivo geral}

Avaliar a qualidade físico-química da água produzida de poços de petróleo no semiárido brasileiro e o seu potencial uso como fonte alternativa para irrigação.

\section{b. Objetivos específicos}

- Caracterizar por meio de ensaios físico-químicos a qualidade da água produzida oriunda da região produtora de petróleo de Mossoró;

- Avaliar a ocorrência de metais na água produzida e as potenciais consequências toxicológicas;

- Caracterizar o cenário ambiental da região de produção da água produzida;

- Avaliar a utilidade da água produzida como alternativa hídrica para irrigação.

\section{METODOLOGIA}

Baseando-se nos objetivos pré-definidos deste artigo, desenvolveu-se a metodologia a ser aplicada. Esta metodologia foi fragmentada em três partes. A primeira etapa diz respeito à elaboração do referencial teórico do artigo; a segunda às análises físico-químicas e de metais das amostras de água produzida; e a terceira aos resultados do trabalho, no qual se apresenta a caracterização da região de origem da água produzida, um comparativo entre os valores das variáveis analisadas e os valores das mesmas variáveis estabelecidas pela lei para irrigação e lançamento de efluente. Todo esse processo pode ser mais bem visualizado na Figura 1.

O estudo ora apresentado foi desenvolvido mediante a análise de água produzida oriunda de quatorze estações de coleta de AP na extração de petróleo cedida pela empresa Partex Oil and Gas. A localização de amostragem encontra-se descrita no mapa 1 da Figura 2. As análises físicas, químicas e toxicológicas realizadas e as referências das suas metodologias são apresentadas na Tabela 1 e na Tabela 2. 


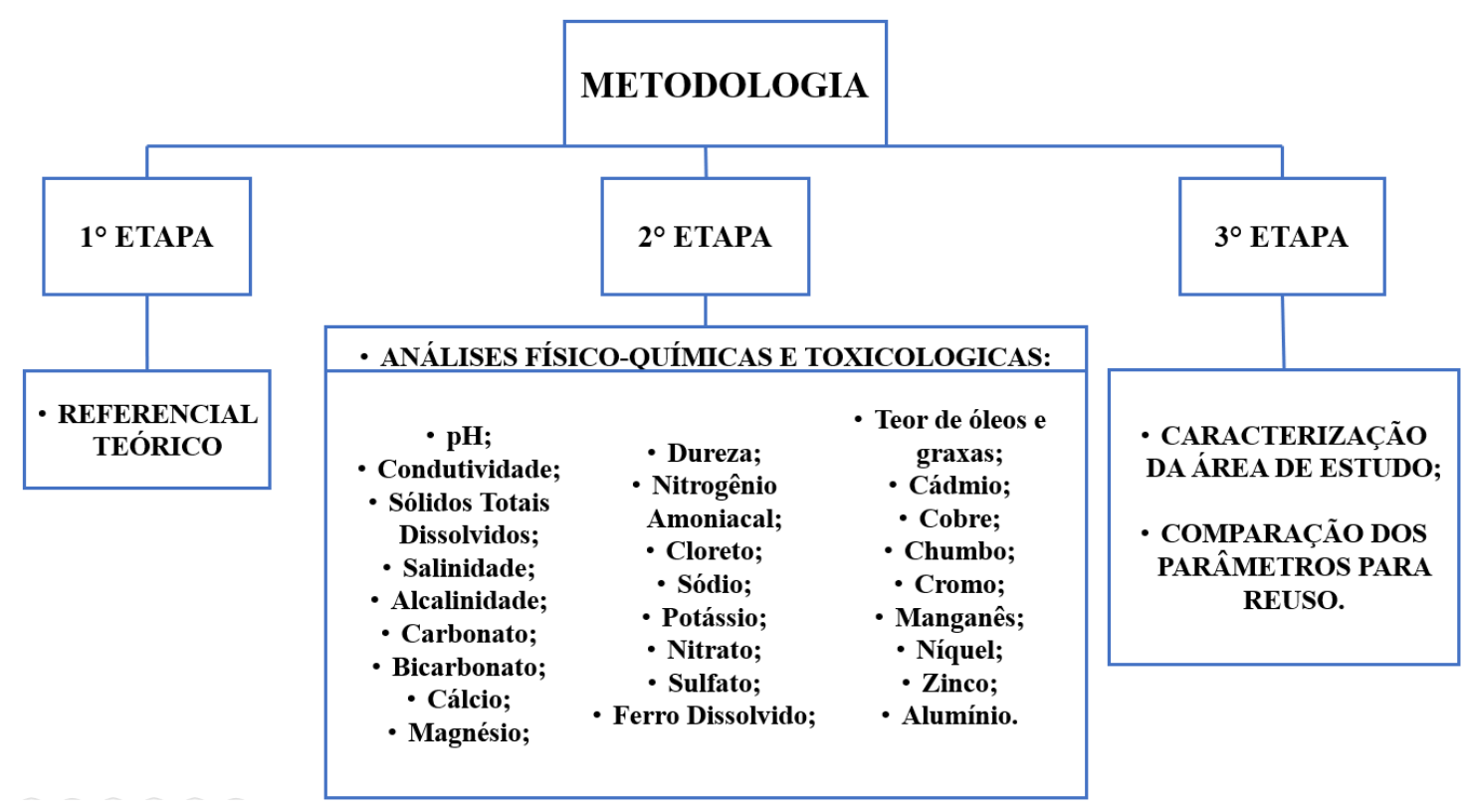

Figura 1: Descrição das etapas metodológicas.

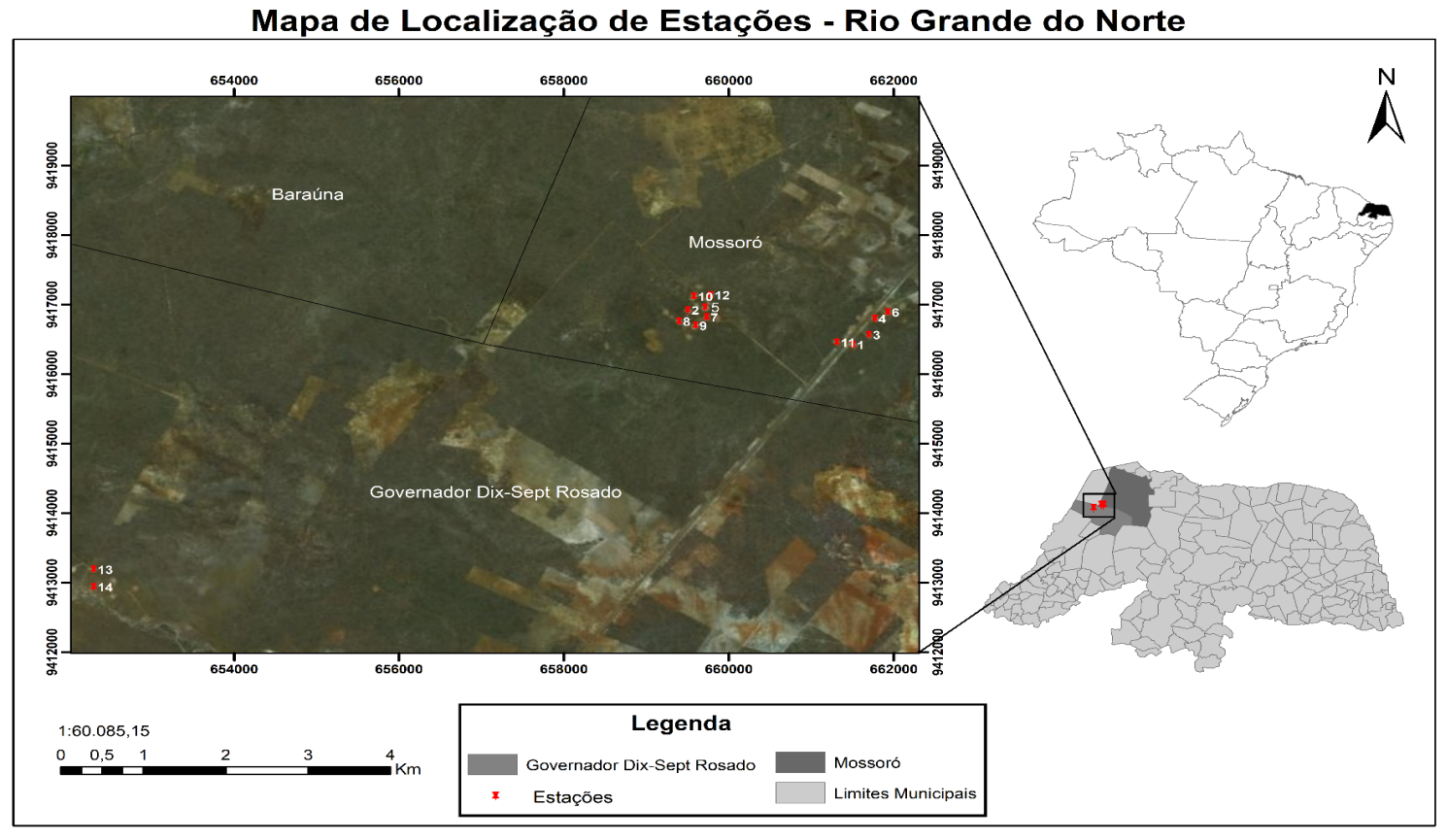

Figura 2: Mapa da Localização das estações de coleta de água produzida

Os resultados obtidos foram avaliados por meio de estatística descritiva e comparados com legislações vigentes de qualidade de água subterrânea ou efluentes, CONAMA 396 e CONAMA 430 respectivamente. Além disso, a análise de conglomerados hierárquicos e a análise de componente principal foram realizadas com o intuito de descrever e caracterizar as amostras de água a partir dos parâmetros aferidos. O software usado foi o SPSS versão 20. 
Tabela 1: Metodologia utilizada nas análises físico-químicas.

\begin{tabular}{c|c}
\hline VARIÁVEIS & $\begin{array}{c}\text { REFERÊNCIAS DAS } \\
\text { METODOLOGIAS UTILIZADAS }\end{array}$ \\
\hline Condutividade & APHA - 2510 A, B \\
\hline pH & APHA $-4500-\mathrm{H}^{+}$ \\
\hline $\begin{array}{c}\text { Sólidos totais Dissolvidos } \\
\text { (TDS) }\end{array}$ & APHA - 2540 A, C, E \\
\hline Alcalinidade Total & APHA - 2320 \\
\hline Dureza & APHA - 2340 A, C \\
\hline Nitrato & APHA - 4500-NO3 - A, B \\
\hline Sódio & APHA - 3500 - Na, B \\
\hline Potássio & APHA - 3500 - K, B \\
\hline Cálcio & APHA - 3500 - Ca \\
\hline Magnésio & APHA - 3500 -Mg \\
\hline Ferro Dissolvido & APHA - 3500 - Fe \\
\hline Carbonato & APHA - 2320 \\
\hline Bicarbonato & APHA - 2320 \\
\hline Sulfato & APHA - 4500 A, E \\
\hline Cloreto & APHA - 4500 - Cl - A, B \\
\hline Salinidade & APHA - 2520 \\
\hline
\end{tabular}

(1) - METODOLOGIA UTILIZADA: APHA et al. (2012). Standard Methods for the

Examination of Water and Wastewater. 22th Washington DC: American Public Health

Associations, 2012.

Tabela 2: Metodologia utilizada nas análises toxicológicas.

\begin{tabular}{c|c}
\hline VARIÁVEIS & TÉCNICA UTILIZADA $^{1}$ \\
\hline Teor de Óleos e Graxas (TOG) & APHA - 5520 A, D \\
\hline Metais Pesados & APHA - 3000; 3500 \\
\hline
\end{tabular}

(1) - MEtOdologiA UTILIZADA: APHA et al. (2012). Standard Methods for the Examination of Water and Wastewater. 22th Washington DC: American Public Health Associations, 2012.

\section{RESULTADOS E DISCUSSÕES}

Este trabalho apresenta o cenário sobre a qualidade da água produzida oriunda do município de Mossoró/RN, a partir da avaliação nas estações coletoras no que tange as análises físico-químicas e toxicológicas com perspectiva de reúso dessa água para irrigação. Na Tabela 3, encontra-se a descrição geral dos resultados físico-químicos obtidos.

A condutividade elétrica é a variável que descreve a capacidade que a água tem de conduzir corrente elétrica. Associada ao total de sólidos dissolvidos (TSD), ela fornece uma medida quantitativa do total de sais dissolvidos na água de irrigação (Silva, Fontes, Tavella, \& Oliveira, 2011). Os valores máximos foram encontrados nos pontos 01 e 13, mas os resultados obtidos estiveram abaixo dos limites máximos estabelecidos pela legislação para irrigação.Os 
sólidos, por sua vez, são os diferentes tipos de partículas que estão presentes na água e podem ser sólidos suspensos ou dissolvidos (Silva et al., 2011). Sobre esses sólidos totais dissolvidos, os resultados estiveram dentro do permitido pela legislação. Novamente, as estações 01 e 13 apresentaram os maiores níveis observados para essa variável.

A salinidade é um indicativo do teor total de sais existente em uma amostra de água. Os resultados obtidos, no que diz respeito ao reúso para irrigação, também estiveram dentro dos limites legais e, novamente, os maiores valores foram obtidos nas estações 01 e 13 . Em relação ao cloreto, $85 \%$ dos resultados estão dentro dos limites legais para o reúso em irrigação. Já os níveis de nitrato e de sulfato apresentaram valores dentro dos limiares legais para água de reúso, com os valores máximos para este último encontrados nas estações 06 e 12.0s maiores valores de alcalinidade foram obtidos nas estações 03 e 06 . Não há valores limites legais para a alcalinidade quanto ao reúso agrícola. $\mathrm{Na}$ análise, não se identificou a presença de carbonato nas amostragens. No entanto, os valores de bicarbonato estiveram acima do limite estipulado pela legislação para irrigação.

Com foco no reúso agrícola, tem-se que todas as amostras estiveram com os valores de sódio dentro dos limites legais, $85 \%$ das amostras quanto à análise de cálcio e apenas $7 \%$ das amostras estiveram com valores de magnésio dentro dos limites legais e em todas as amostras o potássio superou os limites estabelecidos para irrigação.

Tabela 3:Resultados das análises físicas e químicas da água produzida.

\begin{tabular}{|c|c|c|c|c|c|c|}
\hline Variáveis & Máx. & Mín. & Méd & Mediana & EMBRAPA 2018 & $\begin{array}{c}\text { CONAMA } \\
430\end{array}$ \\
\hline $\mathrm{pH}$ & 7,5 & 7,01 & 7,18 & 7,16 & $6,00-8,50$ & $\begin{array}{c}5,00- \\
9,00\end{array}$ \\
\hline Condutividade $(\mu \mathrm{s} / \mathrm{cm})$ & 1246,00 & 577,00 & 689,00 & 609,0 & $0,00-3000,00$ & - \\
\hline TDS (mg/L) & 834,82 & 386,59 & 461,63 & 408,03 & $0,00-2000,00$ & - \\
\hline Salinidade (g/L) & 0,60 & 0,20 & 0,34 & 0,30 & 2000,00 & - \\
\hline Alcalinidade (mg/L) & 221,92 & 73,30 & 169,46 & 173,06 & - & - \\
\hline Carbonato (mg/L) & ND & ND & ND & ND & $0,00-0,60$ & - \\
\hline Bicarbonato (mg/L) & 270,74 & 89,43 & 206,74 & 211,13 & $0,00-78,10$ & - \\
\hline Cálcio (mg/L) & 101,18 & 7,78 & 45,20 & 38,92 & $0,00-89,50$ & - \\
\hline Magnésio (mg/L) & 44,83 & 4,72 & 24,14 & 23,59 & $0,00-17,40$ & - \\
\hline Sódio (mg/L) & 57,20 & 26,30 & 40,05 & 40,50 & $0,00-191,80$ & - \\
\hline Potássio (mg/L) & 19,60 & 13,10 & 16,45 & 16,60 & $0,00-2,00$ & - \\
\hline Dureza (mg/L) & 417,53 & 38,84 & 212,13 & 184,49 & - & - \\
\hline Cloreto (mg/L) & 382,08 & 39,19 & 133,01 & 97,97 & $0,00-178,60$ & - \\
\hline Sulfato (mg/L) & 18,46 & 4,99 & 12,17 & 11,77 & $0,00-138,60$ & - \\
\hline Nitrato (mg/L) & 0,13 & 0,00 & 0,03 & 0,00 & $0,00-10,00$ & - \\
\hline Ferro Dissolvido (mg/L) & 0,03 & 0,01 & 0,02 & 0,02 & 5,00 & 15,0 \\
\hline
\end{tabular}

-ND - Não detectável pela metodologia utilizada.

-EMBRAPA 2018 - Qualidade da água de irrigação.

-CONAMA № 430 -Resolução $n^{\circ}$ 430, de 13 de maio de 2011.

-Resultados em negrito indicam valores fora dos padrões considerados para comparação. 
A dureza é uma variável que resulta da presença essencialmente de sais alcalinos terrosos (cálcio e magnésio). A água pode ser classificada em termos de dureza (em $\mathrm{CaCO}_{3}$ ) da seguinte forma: < 50 mg/ $\mathrm{L} \mathrm{CaCO}_{3}$ - água mole; entre 50 e $150 \mathrm{mg} / \mathrm{L} \mathrm{CaCO}_{3}$ - água com dureza moderada; entre 150 e 300 mg/ $\mathrm{LaCO}_{3}$ - água dura; 300 mg/L CaCO 3 - água muito dura (Silva et al., 2011). Para o caso das amostras analisadas, $8 \%$ se classificam como água mole, $77 \%$ como água dura e $15 \%$ como água muito dura.

Quanto ao $\mathrm{pH}$ das amostras, é possível visualizar que os valores apresentados pela água produzida já se enquadram dentro da faixa especificada para reúso em irrigação e lançamento de efluente determinado pela lei, observando-se em todos os casos valores semelhantes em torno da neutralidade. Além disso, também foram feitas análises de metais e teor de óleo e graxas (TOG) presentes na água produzida. Os resultados dessas análises são descritos na Tabela 4.

Tabela 4:Descrição geral dos níveis de TOG e metais pesados em amostras de água produzida.

\begin{tabular}{cccccccc}
\hline Variáveis & Máximo & Mínimo & Média & Mediana & $\begin{array}{c}\text { CONAMA No } \\
\mathbf{3 9 6}\end{array}$ & $\begin{array}{c}\text { CONAMA } \\
\text { No 430 }\end{array}$ \\
\hline TOG (mg/L) & 584,640 & 1,710 & 119,510 & 66,670 & - & 20,000 \\
& Cádmio & ND & ND & ND & ND & 0,010 & 0,200 \\
& Cobre & 0,020 & 0,000 & 0,000 & 0,000 & 0,200 & 1,000 \\
Metais & Chumbo & ND & ND & ND & ND & 5,000 & 0,500 \\
Pesados & Cromo & ND & ND & ND & ND & 0,100 & 1,000 \\
(mg/L) & Manganês & 0,150 & 0,000 & 0,050 & 0,030 & 0,200 & 1,000 \\
& Níquel & 0,030 & 0,000 & 0,000 & 0,000 & 0,200 & 2,000 \\
& Zinco & 0,060 & 0,000 & 0,010 & 0,000 & 2,000 & 5,000 \\
& Alumínio & 1,030 & 0,050 & 0,340 & 0,26 & 5,000 & - \\
\hline
\end{tabular}

-ND - Não detectável pela metodologia utilizada.

-CONAMA № 396 - Resolução n 396, de 3 de abril de 2008.

-CONAMA № 430 -Resolução n 430, de 13 de maio de 2011.

Todas das amostras apresentaram valores de ferro em conformidade com a legislação para reúso agrícola e lançamento de efluente. Não foi possível detectar a presença de cádmio, chumbo e cromo nas amostras de AP. De maneira geral, todos os metais analisados apresentaram valores que estão abaixo dos limites máximos permitidos para irrigação e destinação no ambiente, segundo as normas usadas como referência.

Para TOG, é possível observar que $77 \%$ das amostras apresentaram resultados superiores a $20 \mathrm{mg} / \mathrm{L}$ e $23 \%$ apresentaram resultados inferiores a $20 \mathrm{mg} / \mathrm{L}$, como é possível observar na Figura 3, com valores variando de 5-9 vezes o valor permitido para o lançamento no ambiente, salientando o resultado obtido na estação 10, onde o valor foi superior a 20 vezes o limiar considerado. Além disso, também foi realizada uma análise cluster hierárquico para se avaliar a semelhança e as diferenças entre as estações de amostragem. Na Figura 4, encontram-se 
representados graficamente os resultados obtidos. Amostras coletadas nas estações 8 e 10, 1 e 13 apresentaram características de qualidade de água diferenciadas com respeito ao resto das amostras analisadas, ratificando as observações previamente descritas.

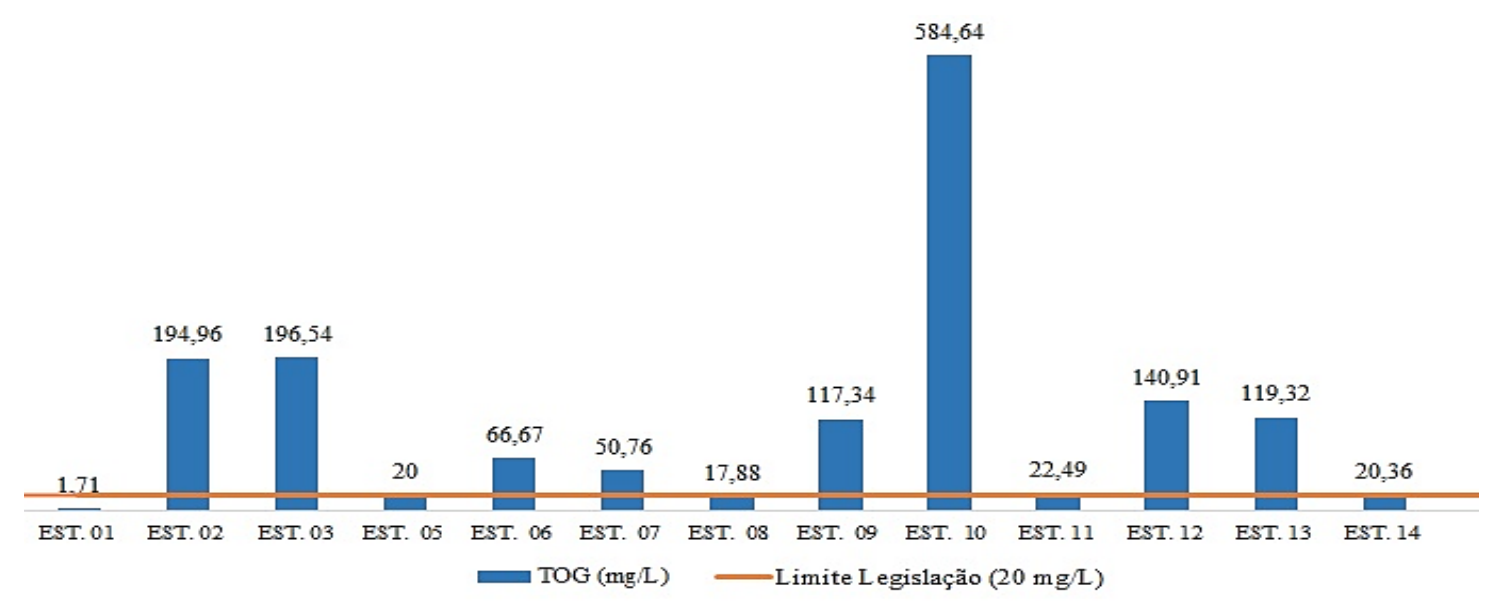

Figura 3: Comparativo TOG das 13 amostras analisadas e limite do CONAMA $n^{\circ} 430$.

Para identificar as variáveis que mais influenciaram no padrão descrito, uma análise de componente principal foi realizada. Três componentes principais foram obtidos e explicaram $80 \%$ da variância total. O primeiro componente foi o mais representativo, explanando $60 \%$ da variabilidade observada, tendo como variáveis mais representativas aquelas correlacionadas com a composição iônica, tais como condutividade elétrica $(0,926)$ e sólidos dissolvidos totais $(0,861)$.

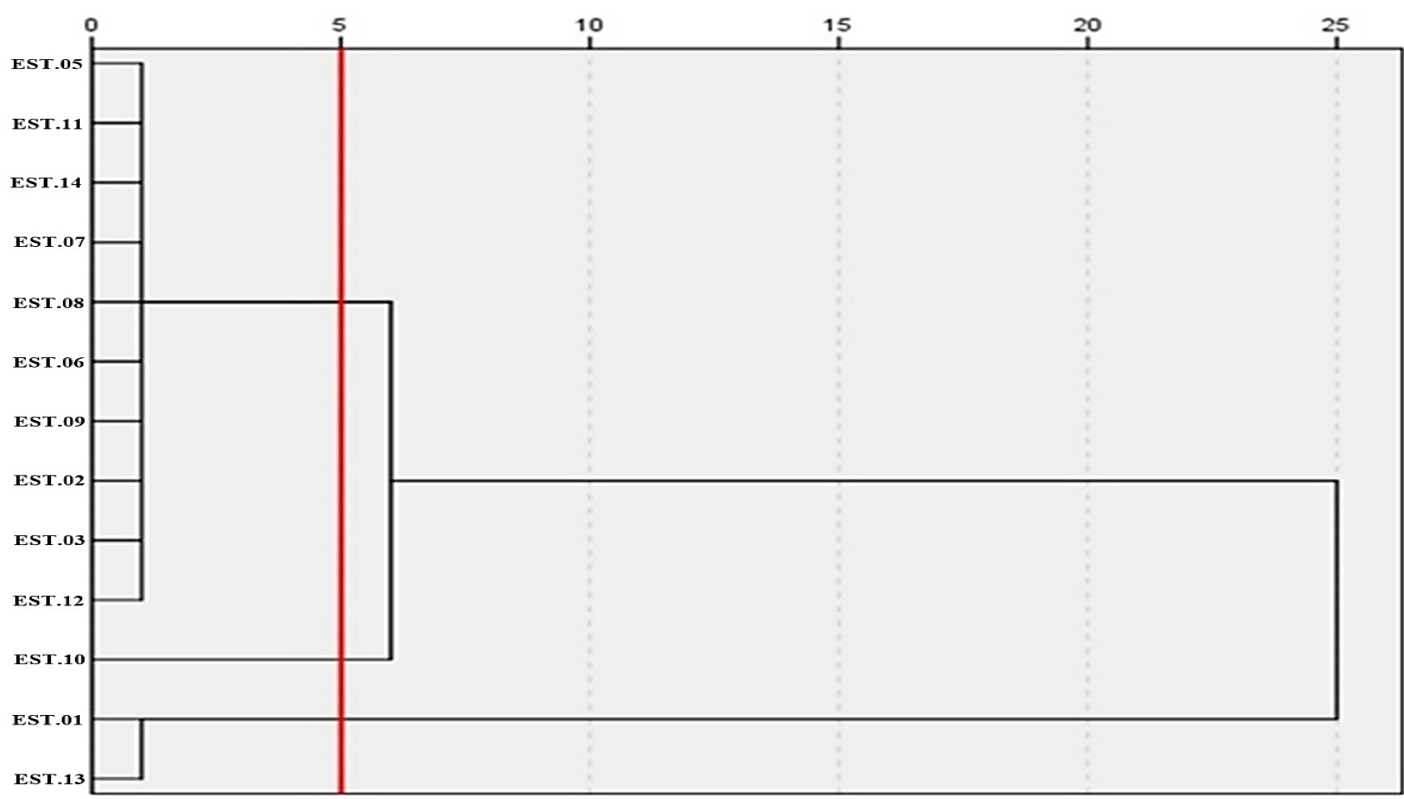

Figura 4:Análise de conglomerados hierárquico. Resultados representados com uso do método de vinculação de

Ward.

Entre os íons mais representativos, figuram bivalentes tais como o $\mathrm{Ca}(0,935)$ e o $\mathrm{Mg}$ $(0,957)$, além do bicarbonato $(0,939)$, o que explicaria a associação observada em relação ao pH $(0,926)$. Os componentes 2 e 3 representaram $20 \%$ da variabilidade explicada particularmente 
associados à ocorrência de íons monovalentes, tais como o cloreto, sódio, potássio e a salinidade $(0,672)$.

Os resultados de $\mathrm{RAS}^{\circ}$ observados foram variáveis, com valores basais de 0,7 até valores máximos superando 0,14 . Todos os pontos apresentaram valores dentro da faixa adequada para irrigação, com os maiores valores encontrados nas estações 01 e 13. Por meio dos valores do $\mathrm{RAS}^{\circ}$ e da $\mathrm{CE}$, as amostras foram caracterizadas de maneira que $85 \%$ delas foram classificadas como C1S2 (Salinidade Baixa e Sodicidade Média) e o remanescente classificado como C2S1 (Salinidade Média e Sodicidade Baixa),descrevendo a qualidade das amostras de água com grau de restrição moderado ao uso, a depender das características do solo e da vegetação irrigada. Os resultados são apresentados na Figura 5.

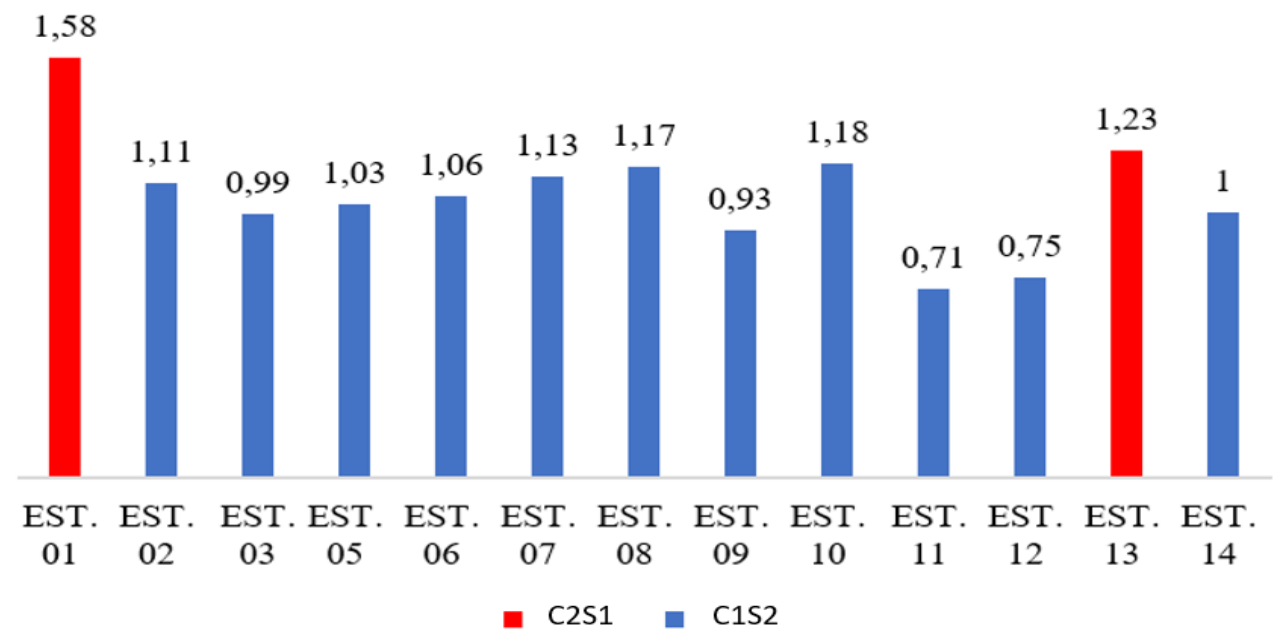

Figura 5:RAS ${ }^{\circ}$ para as estações de coleta de AP com as classificações de salinidade e sodicidade

A AP tem um potencial significativo para reúso como fonte hídrica para áreas desprovidas de água devido aos mássicos volumes gerados, em particular nas regiões semiáridas e com estresse hídrico, como a área objeto de estudo. No entanto, ainda não existe uma legislação que regulamente o uso e a qualidade dessa água para o reúso. Segundo Nasiri, Jafari e Parniankhoy (2017), as características da AP variam a depender do tipo de reservatório, da localização geográfica do campo, da formação geológica e do tipo de hidrocarboneto produzido.A forma de avaliação da viabilidade do reúso da AP dependerá do objetivo final considerado (reúso ou descarte). Os resultados obtidos foram comparados aos limites estabelecidos pela legislação. Bezerra, Parodia, Silva, \& Pergher (2019) desenvolveram, por sua vez, um estudo sobreAP oriunda de área próxima à analisada no presente estudo e os resultados obtidos foram semelhantes aos encontrados nesta pesquisa.

O nitrato presente na água produzida pode advir do contato desta com a formação rochosa ou da transformação de nitrito e nitrogênio amoniacal em nitrato. Esse componente pode contribuir com o aporte de nitrogênio, beneficiando naturalmente a fertilização do solo. Contudo, os valores encontrados neste estudo foram próximos a zero. Baixos valores para esta variável também foram obtidos por Sappington e Rifai (2018), na região do Texas. O pH apresentou valores abaixo de 8,0, o que está relacionado à ausência de carbonatos nas amostras realizadas. 
Nasiri et al. (2017) avaliaram AP de poços petrolíferos no Iran e encontraram alcalinidade entre $300 \mathrm{mg} / \mathrm{L}-380 \mathrm{mg} / \mathrm{L}$ enquanto o bicarbonato de $15 \mathrm{mg} / \mathrm{L}-3501 \mathrm{mg} / \mathrm{L}$, resultados que se assemelham aos encontrados no presente estudo. No tocante aos bicarbonatos, observaram-se, nesta pesquisa, valores acima dos limites da legislação para irrigação. Assim, faz-se necessária a adequação da AP com relação a essa variável em caso de reúso agrícola, pois os íons de bicarbonato, quando em concentrações elevadas, têm tendência de precipitação do cálcio e do magnésio, o que pode causar danos ao solo.

A qualidade da água de irrigação é comumente avaliada pela concentração total de sais dissolvidos e pela sua composição iônica. Os principais sais dissolvidos avaliados na água de irrigação são os de sódio, de cálcio e de magnésio pelo risco de afetar a qualidade do solo (Silva et al., 2011). Normalmente, o potássio e o carbonato estão presentes em proporções relativamente baixas. Entretanto, neste estudo, os níveis elevados de potássio observados contribuem com a salinidade em contraponto ao reportado em outros estudos desenvolvidos na região.

Jiménez et al. (2018) desenvolveram um trabalho no qual é feito um resumo das características da AP em poços petrolíferos de acordo com diferentes referências bibliográficas. As variáveis de $\mathrm{Na}, \mathrm{K}, \mathrm{Ca}$ e $\mathrm{Mg}$ apresentaram, respectivamente, os seguintes limiares: $0 \mathrm{mg} / \mathrm{L}$ $150000 \mathrm{mg} / \mathrm{L}, 24 \mathrm{mg} / \mathrm{L}-4300 \mathrm{mg} / \mathrm{L}, 0 \mathrm{mg} / \mathrm{L}-74000 \mathrm{mg} / \mathrm{L}$ e8 mg/L - $6000 \mathrm{mg} / \mathrm{L} . \mathrm{Na}$ AP analisada neste trabalho, para as variáveis descritas anteriormente, os valores foram similares aos apresentados por Jiménez et al. (2018). A variável de Na não representa um problema. Todavia, para os valores de $\mathrm{K}, \mathrm{Ca}, \mathrm{Mg}$, apesar deles estarem mais próximos do mínimo apresentado pelo autor, algumas amostras reportaram valores não conformes para reúso na irrigação. Nesse sentido, o tratamento e o controle da qualidade da AP são necessários para diminuir o risco da concentração desses compostos e, por consequência, diminuir o risco de salinização do solo, o que causa impacto direto no desenvolvimento das culturas que serão irrigadas.

Jiménez et al. (2018) também destacam o percentual de anions sulfatos e de cloreto nas amostras de AP. Para o Cl, observou-se um intervalo de $0 \mathrm{mg} / \mathrm{L}-250000 \mathrm{mg} / \mathrm{L}$;e para o $\mathrm{SO}_{4}{ }^{-2}$, limiar de $10 \mathrm{mg} / \mathrm{L}$. O cloreto, no presente estudo, apresentou resultado conforme com o intervalo descrito pelo autor citado; já o sulfato, em seu valor máximo, se aproximou do dobro do valor indicado pelo mesmo autor. O cloreto em seu valor máximo excedeu o valor limite para irrigação, sendo, dessa forma, necessário algum tipo de tratamento que minimize a presença deste contaminante. O sulfato, apesar de ter o dobro do valor apresentado por esses autores, está conforme para irrigação e não precisa de adequação.

Os valores de $\mathrm{RAS}^{\circ}$ estiveram de acordo com a classificação de baixa probabilidade de causar impacto no solo ou na vegetação no que diz respeito à salinidade, pois a classificação C2S1 proporciona o uso no cultivo de plantas moderadamente tolerante aos sais, com irrigação na maioria dos solos. A classificação C1S2 permite irrigação da maioria das culturas em quase todos os tipos de solos. Porém, em solos argilosos, o sódio dessa classe de água apresenta um perigo considerável de dispersão com redução de permeabilidade, o que não impossibilita essas águas de serem utilizadas em solos arenosos ou em solos orgânicos de boa permeabilidade (Silva et al., 2011). 
Uma alta salinidade faz com que a velocidade de infiltração no solo aumente.Em contraponto, uma baixa salinidade ocasiona a redução da velocidade de infiltração. A principal consequência do aumento da salinidade em uma água para irrigação é a seca fisiológica e o desbalanceamento nutricional nos vegetais (Silvaet al., 2011).Dessa forma, considerações sobre o tipo de solo e cultivo a ser irrigado tem de ser considerado previamente, baseado nas características físicas e químicas da AP.

Os autores Campos (2016); Chagas, Sant'Anna, Matos, Lopes e Silva (2012); Sousa et al. (2016) ressalvam, em suas pesquisas, a presença de contaminantes como os compostos orgânicos persistentes e os metais pesados na água produzida, assim como alterações no teor de sólidos dissolvidos e pH podem causar acúmulos desses resíduos nos solos e nos tecidos vegetais, atingindo níveis tóxicos e nocivos. No tocante aos metais, a água produzida pode ter em sua composição a presença de elementos tais como $\mathrm{Fe}, \mathrm{Cr}, \mathrm{Ba}, \mathrm{Ni}, \mathrm{Zn}$ e outros. Contudo, a variedade e a concentração desses metais irão depender de aspectos como: características e idade geológica, volume de água injetada e composição química (Al-Ghouti, Al-Kaabi, Ashfaq \& Da'na, 2019).

Echchelh, Hess e Sakrabani (2018) faz uma avaliação da AP oriunda de poços produtores de petróleo de diferentes locais, apresentando intervalos de metais seguindo os seguintes valores:Cd menor que 0,005 até $0,2 \mathrm{mg} / \mathrm{L}$; $\mathrm{Cr} 0,02$ até $1,1 \mathrm{mg} / \mathrm{L}$; $\mathrm{Cu}$ menor que 0,002 até 1,5 $\mathrm{mg} / \mathrm{L}$; $\mathrm{Mn}$ menor que 0,004 até $175 \mathrm{mg} / \mathrm{L} ; \mathrm{Ni}$ menor que 0,001 até 1,7 mg/L;Pb 0,002 até 8,8 $\mathrm{mg} / \mathrm{L}$; Zn menor que 0,01 até $35 \mathrm{mg} / \mathrm{L}$; Al 310 até $410 \mathrm{mg} / \mathrm{L}$. Os resultados provenientes das análises de AP descritos neste trabalho para os metais citados anteriormente apresentaram valores semelhantes aos apresentados por Echchelh et al. (2018).

Os compostos químicos presentes na AP são potenciais geradores de bioacumulação. Mesmo em baixas concentrações, esses compostos contribuem criticamente para o ecossistema marinho e geram potenciais riscos ecológicos (Lourenço, Oliveira, Souza, Nudi, Wagener, Meniconi, \& Francioni, 2016). Em relação à qualidade da AP, esta se encontra dentro dos limiares indicados para reúso em irrigação de acordo com a legislação vigente no Brasil (CONAMA 396). Apesar da capacidade de bioacumulação dos metais, os baixos percentuais indicados como resultados nesta pesquisa não são significativos para causar danos ambientais e/ou para a saúde humana.

Mesmo com o desenvolvimento de diversas pesquisas a respeito da água produzida, ainda é baixa a relação de trabalhos que avaliam o percentual de compostos orgânicos persistentes ou do percentual de óleo presente na água. Nasiriet al. (2017), por exemplo, mostram um percentual de $92 \mathrm{mg} / \mathrm{L}$ de TOG em sua pesquisa. Do total das amostras de AP analisada neste trabalho, a que apresentou valor máximo chegou a quase 7vezes mais do que o apresentado por esses.

O resultado final apontado para as análises de TOG, de acordo com a metodologia aplicada neste artigo, apresenta o teor de óleos e graxas provenientes de origem vegetal e mineral. É possível observar que, entre os valores máximos e mínimos apresentados pela AP, há uma significativa variação que pode ser decorrente das características individuais de cada poço ou do tempo que o poço está em produção. Isso significa que poços maduros, que estão em produção 
há mais tempo, tendem a ter mais água e menos óleo; já os poços que estão em produção há menos tempo terão um percentual de óleo maior. Ademais,os hidrocarbonetos aromáticos policíclicos (PAHs) podem ser um exemplo dos contaminantes com capacidade de bioacumulação (Lourençoet al., 2016).

Vale ressaltar que essa água não recebeu nenhum tipo de tratamento e que já na sua fase inicial deve passar por um sistema de tratamento padrão composto por separador água/óleo, flotação por ar dissolvido, decantação lamelar e filtro. Essa atividade de tratamento reduz significativamente o percentual de óleo livre na água, visto que, ao final do processo, o TOG máximo permitido para essa água é de $20 \mathrm{mg} / \mathrm{L}$ (teor permitido pela legislação para descarte de AP - CONAMA 430), uma vez que, se não for reutilizada, seu destino será o descarte.

\section{CONCLUSÕES}

A escassez hídrica é uma problemática que atinge várias regiões no mundo, em particular as zonas semiáridas. A água de reúso é uma alternativa plausível e eficiente para mitigar ao menos em parte este problema. Os grandes volumes de água gerados na atividade extrativista de petróleo podem ser convertidos de uma problemática a uma alternativa de suplementação hídrica. Neste estudo, uma caracterização físico-química da água produzida foi realizada de forma a avaliar a adequação ou não adequação as normas vigentes. No entanto, a sua utilização como recurso hídrico alternativo após tratamento é aceitável. Estudos dirigidos que busquem avaliar a sustentabilidade da implementação de tecnologias quanto à avaliação da eficiência da dessalinização e a remoção de compostos orgânicos persistentes serão necessário de se avaliar em estudos futuros.

\section{REFERÊNCIAS}

AL-GHOUTI, M. A. et al. (2019). Produced water characteristics, treatment and reuse: A review. Journal Of Water Process Engineering, 28, 222-239.

APHA, AWWA E WEF - AMERICAN PUBLIC HEALTH ASSOCIATION; 757 AMERICAN WATER WORKS ASSOCIATION; WATER ENVIRONMENT 758 FEDERATION. Standard methods: for the examination of water and wastewater. (759 22a nded.) Washington: American Public Health Association, 2012.

ASSUNÇÃO, M. V. D. et al. (2018). Fatores influenciadores na produção indesejada da água produzida de petróleo: um estudo na bacia Potiguar/Brasil. Revista Holos, v. 2, 146-160.

BEZERRA, B. G. P. et al. (2019). Cleaning produced water: A study of cation and anion removal using different adsorbents. Journal Of Environmental Chemical Engineering, 7(2), 103006103014. BRASIL. Agência nacional de petróleo gás natural e biocombustíveis. (2017) Produção por poço. Disponível em: <http://www.anp.gov.br/dados-estatisticos >. Acesso em: 10 abr. 2018. 
BRASIL. Resolução $n^{\circ}$ 430, de 2011. Resolução CONAMA no 430/2011. Brasília. Disponível em: <http://www.mma.gov.br/port/conama/legiabre.cfm?codlegi=646>. Acesso em: $30 \mathrm{abr}$. 2018.

BRASIL. Resolução no 15, de 11 de janeiro de 2001. Resolução no 15, de 11 de Janeiro de 2001. Brasília. Disponível em: <http://www.sema.df.gov.br/wpconteudo/uploads/2017/09/Resolu\%C3\%A7\%C3\%A3o-CNRH-n\%C2\%BA-15-de-2001.pdf>. Acesso em: 22 nov. 2018.

BRASIL. Resolução no 357, de 2008. Resolução CONAMA no 357/2005. Brasília. Disponível em: <http://www2.mma.gov.br/port/conama/legiabre.cfm?codlegi=459>. Acesso em: 22 nov. 2018.

BRASIL. Resolução no 396, de 2008. Resolução CONAMA no 396/2008. Brasília. Disponível em: <http://www.mma.gov.br/port/conama/legiabre.cfm?codlegi=562>. Acessoem: 09 abr. 2018

CAMPOS, L. C. (2016). Importancia de la caracterización de aguas producidas en la industria petrolera. Geominas, Venezuela, 44(71), 171-175.

CHAGAS, R. R. A., SANT'ANNA, M. C. S., MATOS, D. B. de, LOPES, D. F. C., \& SILVA, G. F. (2012) Monitoramento tecnológico das técnicas de tratamento de água produzida. Revista Gestão, Inovação e Tecnologia, 2(3), 214-220.

COMPANHIA DE PESQUISA DE RECURSOS MINERAIS - CPRM (Brasil). (2018). Serviço Geológico do Brasil. Disponível em: <http://www.cprm.gov.br/>. Acessoem: 22 nov. 2018.

DOLAN, F. C., CATH, T. Y., \& HOGUE, T. S. (2018). Assessing the feasibility of using produced water for irrigation in Colorado. Science Of The Total Environment, 640-641, 619-628. ECHCHELH, A., HESS, T., \& SAKRABANI, R. (2018). Reusing oil and gas produced water for irrigation of food crops in drylands. Agricultural Water Management, 206, 124-134.

GARNICA, A. I. Curbelo et al. (2017). Remoção do óleo da água produzida utilizando o carvão ativado comercial Revista Holos, v. 8, 12-31.

GOMES, A. P. P. (2014). Gestão ambiental da água produzida na indústria de petróleo: melhores práticas e experiências internacionais. (Dissertação de mestrado) - Curso de Planejamento Energético, Universidade Federal do Rio de Janeiro, Rio de Janeiro. Disponível em: <http://www.ppe.ufrj.br/ppe/production/tesis/gomes_ana.pdf>. Acessoem: 10 abr. 2018.

HOSNY, R, FATHY, M., RAMZI, M., ABDEL M. T., DESOUKY, S. E. M., \& SHAMA, S. A. (2016). Treatment of the oily produced water (OPW) using coagulant mixtures. Egyptian Journal of Petroleum,25(3), 391-396.

JIMÉNEZ, S., MiCó, M. M., ARNALdOS, M., FERRERO, E., MAlfeito, J. J., MEDinA, F., \& CONTRERAS, S. (2017). Integrated processes for produced water polishing: Enhanced flotation/sedimentation combined with advanced oxidation processes. Chemosphere, 168, 309-317. 
JIMÉNEZ, S., MiCó, M. M., ARNALdOS, M., FERRERO, E., MAlfeito, J. J., MEDINA, F., \& CONTRERAS, S. (2018). State of the art of produced water treatment. Chemosphere, 192, 186-208.

LI, G., GUO, S., ZHANG, J., \& LIU, Y. (2014). Inhibition of scale buildup during produced-water reuse: Optimization of inhibitors and application in the field. Desalination, 351, 213-219.

LOURENÇO, R. A. et al. (2016). Monitoring of polycyclic aromatic hydrocarbons in a produced water disposal area in the Potiguar Basin, Brazilian equatorial margin. Environmental Science And Pollution Research, 23(17), 17113-17122. MALLANTS, D., SIMUNEK, J., \& TORKZABAN, S. (2017). Determining water quality requirements of coal seam gas produced water for sustainable irrigation. Agricultural Water Management, 189, 52-69.

MANCUSO, P. C. S., SANTOS, H. F. (2003.) (Ed.). Reúso de água. Barueri: Manole, 2003.

MARTINS, E. S. P. R., MAGALHÃES, A. R., \& FONTENELE, D. (2017). A seca plurianual de 2010 2017 no Nordeste e seus impactos. Parc. Estrat, v. 22, 17-40.

NASIRI, M., JAFARI, I., \& PARNIANKHOY, B. (2017). Oil and Gas Produced Water Management: A Review of Treatment Technologies, Challenges, and Opportunities. Chemical Engineering Communications, 204(8), 990-1005.

SAPPINGTON, E. N., \& RIFAI, H. S. (2018). Low-frequency electromagnetic treatment of oilfield produced water for reuse in agriculture: effect on water quality, germination, and plant growth. Environmental Science And Pollution Research, 25(34), 34380-34391.

SILVA, Í. N., FONTES, L, O.,TAVELLA, L. B., OLIVEIRA, J. B., \& OLIVEIRA, A. C. (2011). QUALIDADE DE ÁGUA NA IRRIGAÇÃO. Agropecuária Científica no Semi-Árido, 7( 3), 1-15.

SOUSA, A. F., CRISOSTOMO, L. A., WEBER, O. B., ESCOBAR, M. E. O.,\& OlIVEIRA, T. S. (2016). Nutrientcontent in sunflowersirrigatedwithoilexplorationwater. Revista Caatinga, 29(1), 94100.

SRIKANTH, S., KUMAR, M., \& PURI, S. K. (2018). Bio-electrochemical system (BES) as an innovative approach for sustainable waste management in petroleum industry. Bioresource Technology, v. 1, 1-13.

UNITED STATES OF AMERICA. Resolução no P.L. 107-303, de 27 de novembro de 2002. Federal Water Pollution Control Act. United States of America. Disponívelem: $<$ https://www.epa.gov/sites/production/files/2017-08/documents/federal-water-pollutioncontrol-act-508full.pdf>. Acessoem: 22 nov. 2018.

VENKATESAN, A., \& WANKAT, P. C. (2017).Produced water desalination: An exploratory study. Desalination, 404, 328-340. 